\title{
Saturated Fat Consumption and Risk of Coronary Heart Disease and Ischemic Stroke: A Science Update
}

\author{
Joyce A. Nettleton ${ }^{a} \quad$ Ingeborg A. Brouwer ${ }^{b}$ Johanna M. Geleijnse ${ }^{c}$ \\ Gerard Hornstra ${ }^{d}$ \\ ${ }^{a}$ ScienceVoice Consulting, Denver, CO, USA; ${ }^{b}$ Vrije Universiteit Amsterdam, Amsterdam, \\ 'Department Agrotechnology and Food Sciences, Wageningen University, Wageningen, and \\ dExperimental Nutrition (ret'd), Maastricht University, Maastricht, The Netherlands
}

\section{Keywords}

Saturated fat - Coronary heart disease $\cdot$ Stroke $\cdot$ Risk factors . Dietary recommendations

\begin{abstract}
At a workshop to update the science linking saturated fatty acid (SAFA) consumption with the risk of coronary heart disease (CHD) and ischemic stroke, invited participants presented data on the consumption and bioavailability of SAFA and their functions in the body and food technology. Epidemiological methods and outcomes were related to the association between SAFA consumption and disease events and mortality. Participants reviewed the effects of SAFA on CHD, causal risk factors, and surrogate risk markers. Higher intakes of SAFA were not associated with higher risks of CHD or stroke apparently, but studies did not take macronutrient replacement into account. Replacing SAFA by cis-polyunsaturated fatty acids was associated with significant $C H D$ risk reduction, which was confirmed by randomized controlled trials. SAFA reduction had little direct effect on stroke risk. Cohort studies suggest that the food matrix and source of SAFA have important health effects.

(c) 2017 The Author(s)

Published by S. Karger AG, Basel
\end{abstract}

\section{KARGER}

E-Mail karger@karger.com www.karger.com/anm

\section{Introduction}

For decades, the consumption of long-chain saturated fatty acids (SAFA; containing 12-18 carbon atoms) was thought to undermine cardiovascular health. However, recent meta-analyses of prospective observational studies $[1,2]$ reported that SAFA intake was associated with neither coronary heart disease (CHD) nor stroke mortality nor myocardial infarction. Instead, reduced SAFA intake that was replaced by cis-polyunsaturated fatty acids (PUFA) was associated with a $17 \%$ lower risk of cardiovascular events [3], which was confirmed by randomized controlled trials $[4,5]$. Under isoenergetic conditions, the lack of association of SAFA per se with CHD risk could imply that the potential contribution of dietary SAFA is comparable to that of all other macronutrients together. On the other hand, SAFA consumption significantly increases the plasma concentration of low-density lipoprotein cholesterol (LDL-C) compared with mixed carbohydrates and cis-unsaturated fatty acids [6], potentially increasing the risk of CHD [7].

The contrasting findings have challenged current SAFA recommendations, generated vigorous debate, and

Dr. Joyce A. Nettleton

ScienceVoice Consulting 2931 Race Street

Denver, CO 80205 (USA)

E-Mail sciencevoice1@gmail.com
This article is licensed under the Creative Commons Attribution NonCommercial-NoDerivatives 4.0 International License (CC BYNC-ND) (http://www.karger.com/Services/OpenAccessLicense) tribution of modified material requires written permission. 
led to consumer confusion $[8,9]$. Therefore, to update and discuss the science linking SAFA consumption to the risk of $\mathrm{CHD}$ and ischemic stroke, 20 international experts on dietary fat and health convened in Leiden, The Netherlands, November 5-6, 2015, as guests of the International Expert Movement to Improve Dietary Fat Quality (www.theiem.org), The Netherlands Oils and Fats Industry (www.mvo.nl) and the European Palm Oil Alliance (www.palmoilandfood.eu). This updated report describes the meeting's highlights.

\section{SAFA Background}

SAFA intake is inevitable as these fatty acids occur in all fat-containing foods, for example, dairy products, butter, meats, and some vegetable fats and oils [10]. Most dietary SAFA have 12-18 carbon atoms, with foods varying in the relative amounts of individual SAFA. Palmitic (C16) and stearic acids (C18) are predominant in butter, dairy and meat products; lauric (C12) and myristic (C14) acids in butter, dairy foods, coconut, and palm kernel oils [11]. In many Western countries, in particular, SAFA intakes exceed $10 \% \mathrm{E}[10,12]$.

In animal fats, SAFA are mainly located at the $s n-2$ position of the glycerol backbone, whereas they are usually located at the $s n-1$ and -3 positions in vegetable fats and oils [13]. These structural differences imply important physical, metabolic, and functional distinctions, which can be removed by the technique of fatty acid randomization [14].

Coconut oil contains $>80 \%$ SAFA. A common misconception is that the medium-chain SAFA in coconut oil are metabolized differently from long-chain SAFA $(\geq \mathrm{C} 12)$. However, coconut oil contains approximately $50 \%$ lauric acid and $15 \%$ myristic acid, both of which have potent LDL-C and high-density lipoprotein cholesterol (HDL-C)-raising effects [6]. The popular belief that coconut oil is healthy is not supported by scientific data [15].

SAFA have distinct metabolic functions, including protein acylation [16]. This widely occurring mechanism controls the function of diverse proteins and physiological processes. Palmitate and myristate are involved in G-protein activation and consequently in signal transduction [17]. Myristoylation may be involved in the synthesis of ceramide and consequently in sphingolipid metabolism and function [18]. In addition, by stimulating fatty acid desaturation, myristic acid may increase the conversion of essential fatty acids to their functional long-chain polyunsaturated derivatives [19]. Despite

Update on Saturated Fat, CHD and Stroke these important functions, SAFA are not essential fatty acids because they can be synthesized de novo.

SAFA-rich triglycerides (TG) confer several functional qualities to foods, including structure, plasticity, and organoleptic characteristics, such as creaminess and flavor. These qualities enhance food palatability, stability, and structure and are difficult to replace without losing important food characteristics [20]. Many of the functional qualities of SAFA depend on the underlying, spacefilling, fat crystal network that generates macroscopic hardness and stabilizes the oil/water interface [21]. Differences in the fatty acid composition of the TG, for example, chain length and saturation, affect product hardness [22]. For many applications, a SAFA-rich fraction of palm oil (palm stearin) is suitable [23]. Full hydrogenation of vegetable oils rich in unsaturated fatty acids is another option, but conflicts with consumers' demand for minimal processing. Whether this demand can possibly be met by conventional selective plant breeding deserves study.

\section{Risk Factors for CHD and Ischemic Stroke}

Clinicians assess several characteristics to determine an individual's risk of CHD. Those causally related to the risk of CHD are known as risk factors. Changes in a risk factor change CHD risk in a predictable way. Established and modifiable risk factors for CHD include elevated LDL-C, high blood pressure (BP), overweight and obesity, and smoking [24]. Additional risk factors have been suggested, for example, TG and C-reactive protein, but whether they are causally related to CHD is not agreed. Mendelian randomization studies may be useful for establishing causality [25].

Substantial evidence implicates LDL-C as a causal factor in cardiovascular disease (CVD) and CHD events [7], and randomized controlled trials with LDL-lowering interventions [26] support a causal relationship between LDL-C and CHD. However, LDL-C is just one causal risk factor; consequently, many CVD patients can have LDL$\mathrm{C}$ levels in the optimal range. Although observational studies often fail to demonstrate significant correlations between SAFA consumption and LDL-C levels, these do not necessarily exclude a causal relationship [27]. Thus, control of LDL-C remains a cornerstone of CHD risk management [28].

Plasma LDL-C includes the cholesterol in all LDL particles (LDL-P), which exist along a continuum of sizes and densities [29]. Small, dense LDL-P (sdLDL) contain 
less cholesterol per particle, but are more strongly associated with increased CHD risk than larger, more buoyant particles [30]. Thus, the measurement of LDL-P might improve the predictability of $\mathrm{CHD}$ risk compared with LDL-C, particularly when LDL-C is not elevated [31].

The size distribution of LDL-P is affected by the consumption of excess energy and the macronutrient composition of the diet $[32,33]$. Higher intake of SAFA was associated with increases in larger, more buoyant LDL-P [34]. In the context of the Dietary Approaches to Stop Hypertension diet [35], higher compared with lower (14\%E vs. $8 \% \mathrm{E})$ dietary SAFA was associated with improved lipid profiles and lower BP [36] when SAFA replaced carbohydrates. Although the cholesterol content of sdLDL is useful, the overall plasma concentration of these particles may be more informative [37].

There is compelling evidence that individuals with lower HDL-C face a significantly higher risk of CHD [38], but paradoxically, higher levels are not always associated with lower CHD risk [39]. The Emerging Risk Factor Collaboration showed that the inverse relationship between HDL and CHD risk holds only for lower HDL concentrations and does not apply at higher levels. HDL is widely thought to be involved in "reverse cholesterol transport" [40], a hypothesis that has been seriously challenged [41]. Doubts about the "HDL hypothesis" and the causal involvement of HDL-C in CHD risk were strengthened by Mendelian randomization studies in individuals with genetically linked elevated HDL-C whose risk of myocardial infarction was not different from those lacking the variant gene [41, 42]. Furthermore, trials with substances increasing HDL-C levels failed to reduce cardiovascular events or increased them and mortality [43]. However, these trials were performed in patients at high risk of $\mathrm{CHD}$, whose HDL may have lost its putative cardioprotective function $[44,45]$. These findings favored the view that HDL functions beyond cholesterol efflux may be more important for cardiovascular protection than absolute HDL levels [46].

The third commonly assessed lipid marker of CHD risk is plasma TG, chauffeured in particles of chylomicrons and their remnants, very low- and intermediatedensity lipoproteins $[46,47]$. Many studies reported significant associations between fasting and nonfasting TG concentrations and risk of CHD [48, 49], but there is disagreement whether TG-rich lipoproteins constitute an independent causal risk factor $[49,50]$. The difficulty in establishing causality relates to the close relationship between TG and remnant cholesterol, and the inverse relationship between TG and HDL-C concentrations in plas- ma, both of which are significantly associated with the risk of ischemic heart disease, but in opposite directions [51]. In addition, these relationships are confounded by lifestyle factors, such as physical activity, alcohol consumption, higher body mass index, diabetes, and by reverse causation $[52,53]$. Because most cells can degrade TG, but not cholesterol, it is likely that the atherogenic part of TG-rich lipoproteins is cholesterol, not the TG itself. This implies that the plasma TG level could be a risk marker rather than a causal factor.

TG-rich lipoproteins carry 2 specific apolipoproteins on their surface, apolipoprotein $\mathrm{A}-\mathrm{V}$ and apolipoprotein C-III, encoded by the genes APOA 5 and $A P O C 3$, respectively. APOA5 activity lowers circulating levels of TGrich lipoproteins and is associated with decreased risk of CHD $[54,55]$. In contrast, $A P O C 3$ activity mediates higher levels of TG-rich lipoproteins and some of its gene polymorphisms are associated with increased risk of CHD [56]. Certain variants of the APOA5 gene diminish apolipoprotein $\mathrm{A}-\mathrm{V}$ function, which leads to increased TG levels and increased risk of CHD [54]. Individuals with certain loss-of-function mutations in the APOC3 gene had lower TG levels and a lower risk of CHD compared with non-carriers [57]. Thus, data in individuals with specific gene variants lead either to elevated or reduced TG or TG-rich lipoprotein levels, supporting a causal association between TG, remnant cholesterol, and risk of CHD. Unfortunately, there are no large randomized clinical trials that could verify this hypothesis.

A clutch of hemostatic factors and inflammatory mediators $[58,59]$, as well as elevated BP [60] and disturbed endothelial cell function [61], is also associated with CHD risk. Fibrinogen, a positive acute phase protein essential for clot formation, has a long and consistent association with $\mathrm{CHD}$ risk [62]. Its association with $\mathrm{CHD}$ might reflect its responsiveness to inflammation $[58,59]$, but clot formation and the presence of fibrin in atherosclerotic plaque suggest a more direct influence on CHD risk [63, 64]. Still, a multiethnic meta-analysis of genome-wide association studies reported no strong evidence of a causal relationship between fibrinogen and coronary artery disease, stroke, or venous thromboembolism [65]. Evidence that factor VII, also essential for clot formation, is associated with CHD is inconsistent [66, 67]. Other hemostatic factors, such as von Willebrand factor, fibrin D-dimer, and tissue plasminogen activator antigen, appear to be modestly associated with first-ever CHD [59, 68]. Several hemostatic factors associated with $\mathrm{CHD}$ are also associated with inflammatory markers, which may confound CHD risk analyses [69]. 


\section{SAFA Consumption and Heart Health}

Although higher SAFA intake might increase CHD risk by increasing plasma LDL-C [70], recent meta-analyses of prospective observational studies $[1,71,72]$ reported that when compensating nutrients were not taken into account, SAFA intake was not associated with CHD or stroke mortality, all-cause mortality, or myocardial infarction. Two large, independent, prospective cohorts of US men and women confirmed this result [73 $]^{1}$. In a prospective Dutch cohort, higher total SAFA consumption was related to lower risk of ischemic heart disease, but not to CHD risk [74]. In another Dutch cohort, a positive association was observed between CHD risk and palmitic acid, but not total SAFA intake [75].

Several experimental conditions and methodological shortcomings could have obscured a potential relationship between SAFA intake and CHD risk. These include limited range of SAFA intakes within cohorts, possible heterogeneity in the health effects of different fatty acids, and large measurement errors in estimating dietary SAFA intake, without the ability to discriminate among individual fatty acids [76]. The balance among different fatty acids within the fatty acid class may be important [77], as might the food sources of SAFA. Biomarker studies have reported positive associations for CHD between blood levels of even-chain SAFA and inverse associations with odd-chain SAFA, which reflect different food sources [77].

Observational $[3,73]$ and intervention studies [5] have shown clearly that the partial replacement of dietary SAFA with cis-PUFA is associated with significantly reduced $\mathrm{CHD}$ risk and mortality. A recent review and metaanalysis [6] of intervention studies concluded that lowering SAFA intake significantly reduced the risk of combined cardiovascular events, but not mortality. In subgroup analyses, only the partial replacement of SAFA by PUFA reduced CHD events significantly, but replacement with cis-monounsaturated fatty acids (MUFA), carbohydrate, or protein had no significant effect. Another review of observational and intervention studies of partially replacing SAFA with PUFA found convincing evidence of lower blood LDL-C levels and a reduced risk of CVD, especially in men [78].

According to a meta-analysis of 84 controlled trials [6], isocaloric replacement of mixed carbohydrates by a

\footnotetext{
${ }^{1}$ While this paper was in revision, re-analyses of these cohorts were unable to verify this finding. In contrast, a positive association between SAFA intake and CHD risk was observed [98].
}

Update on Saturated Fat, CHD and Stroke common dietary SAFA mixture markedly increased plasma LDL-C and apoB concentrations, indicating an increase in LDL-P number. In addition, levels of HDL-C and apo A-I increased and plasma TG decreased. Isocaloric replacement of carbohydrate by SAFA did not significantly affect the plasma total-C to HDL-C ratio. Data on the effect of SAFA on LDL-P composition and size are scarce, but suggest that higher SAFA consumption mainly increases the larger, more buoyant, less atherogenic LDL-P [32, 33, 79].

Compared with carbohydrates, lauric, myristic, and palmitic acids differently increase LDL-C and HDL-C levels and decrease TG concentrations, while stearic acid does not affect these lipoproteins [6]. Myristic acid has the strongest effect, but because of its much higher intake, palmitic acid has the greatest overall effect on plasma lipoprotein levels. The different effects of individual SAFA explain why dietary fats with different fatty acid compositions vary in their potency to alter lipid and lipoprotein levels.

Specific food sources of SAFA and other macronutrients appear related to CHD risk as suggested by the Multi-Ethnic Study of Atherosclerosis (MESA) [80] and a meta-analysis of milk and dairy consumption [81]. In a meta-analysis of 5 randomized controlled trials [82], cheese compared with butter intake was associated with significant reductions in LDL-C and HDL-C, but had no effect on TG. In the 10-year MESA study, a higher intake of meat-delivered SAFA was associated with greater CVD risk, whereas dairy SAFA was related to lower CVD risk [80]. The investigators estimated that the isocaloric replacement of $2 \% \mathrm{E}$ from meat SAFA with dairy SAFA was significantly associated with a $25 \%$ lower risk of CVD. As the food matrix may also influence the kinetics of SAFA absorption [83], these results indicate that total foods are more important in terms of CHD risks than the SAFA they contain.

As reviewed some time ago [84], the consumption of dietary fat significantly increased the postprandial amounts, activation, and activity of plasma clotting factor VII, which seemed to be associated with the degree of lipemia. Interestingly, the effects of SAFA-rich fats were less pronounced than those of fats rich in MUFA, and were further reduced by fatty acid randomization.

Up-to-date comprehensive reviews covering the effects of dietary fats on platelet function and thrombosis are lacking. Systematic studies with a well-validated rat model of arterial thrombosis revealed that, compared to unsaturated fatty acids, dietary SAFA (but not stearic acid) promote an arterial thrombosis tendency [85]. Ef- 
fects of dietary SAFA on human platelet thrombotic functions have been studied repeatedly with inconsistent results [86]. An FAO/WHO review concluded that dietary SAFA possibly raises BP compared to unsaturated fatty acids [70]. The evidence for different effects of SAFA on flow-mediated dilatation, inflammation, and insulin sensitivity was considered unconvincing.

\section{SAFA Intake and Ischemic Stroke}

The cardinal risk factor for stroke is elevated BP. Furthermore, high BP is strongly and progressively associated with risk of $\mathrm{CHD}$, heart failure, peripheral vascular disease, and other serious health conditions $[87,88]$. The Prospective Studies Collaboration, a meta-analysis of data from 61 prospective studies in individuals aged 40-69 years, reported that each $20 \mathrm{~mm}$ of mercury increase in systolic BP above usual was associated with a more than 2-fold difference in stroke mortality and a 2-fold difference in CHD mortality [89]. A meta-analysis of 11 clinical trials of BP-lowering drugs showed that regardless of baseline cardiovascular risk, lowering the $\mathrm{BP}$ reduced the risk of cardiovascular events in all risk groups [87]. Overall, these data and many other studies support a causal relationship between $\mathrm{BP}$ and risk of $\mathrm{CHD}$ and stroke.

Compared with studies on CHD risk, fewer data link SAFA intakes to the risk of ischemic stroke. Moreover, the results of meta-analyses are inconsistent. When replacement nutrients were not considered, dietary SAFA were not significantly associated with the risk of ischemic stroke [1] or mixed types of stroke [2]. In a recent metaanalysis, higher SAFA intakes appeared associated with lower risks of both stroke types [90]. However, significant effects were limited to males, East Asians, participants with lower body mass index, and studies of high quality and long follow-up. A meta-analysis of 7 intervention studies concluded that SAFA reduction had no clear effect on any type of stroke [4]. Although partial replacement of SAFA by PUFA reduced stroke risk in this study by $32 \%$, with only 4 studies and 41 stroke cases, this effect was not significant.

As dairy products are a major source of dietary SAFA, it is notable that a study of 3 large prospective studies reported that dairy fat intake was not significantly related to the risk of stroke risk [91]. In 2 large prospective cohorts, circulating biomarkers of dairy fat intake were not significantly associated with the risk of any type of incident stroke [92]. Replacement of 5\%E from dairy fat with PUFA was associated with a significant $21 \%$ lower risk of stroke, whereas replacement with animal fat other than dairy increased stroke risk by $6 \%$.

A recent systematic review and meta-analysis of 31 prospective cohort studies of dairy intake and risk of $\mathrm{CVD}, \mathrm{CHD}$, and stroke reported significant inverse relative risks for intakes of total dairy, cheese, and calcium from dairy foods and total stroke, but dose-response associations did not hold after adjustment for within-study covariance [93]. Another meta-analysis of prospective studies reported a significant inverse association between stroke and low-fat dairy and cheese consumption [94]. The investigators noted heterogeneity and publication bias in the studies on stroke.

Thus, the available evidence suggests that SAFA reduction has little, if any, direct effect on stroke risk, but that the consumption of SAFA-rich dairy foods may be associated with a lower risk of ischemic stroke. This topic deserves more thorough investigation [4].

\section{Dietary Guidelines for SAFA}

Dietary guidelines now focus on foods and dietary patterns to improve consumer understanding of more healthful food choices and to acknowledge food matrix and nutrient interactions. Examples include the Nordic Nutrition Recommendations [95], 2015-2020 Dietary Guidelines for Americans [96], and 2015 Dutch foodbased dietary guidelines [97]. There is now convincing evidence that the partial replacement of SAFA-rich foods with those rich in cis-PUFA is associated with a significant reduction in CHD risk. Specific SAFA-rich foods such as dairy products may also be associated with lower CHD risk. Identifying healthy food choices to replace specific, less healthy ones, as in several updated dietary guidelines, may facilitate dietary modifications that lower the risk of $\mathrm{CHD}$.

\section{Summary and Conclusions}

SAFA have important metabolic functions, but their consumption is not essential because they can be synthesized de novo. However, their functional properties make them virtually indispensable for the production of fatcontaining foods. Dietary SAFA, when compared to carbohydrates and cis-unsaturated fatty acids, raise plasma LDL-C, a causal risk factor for CHD. Individual SAFA affect plasma lipoprotein levels differently, with each major dietary SAFA except stearic acid resulting in higher 
levels of LDL- and HDL-C and lower levels of TG. In prospective observational studies and randomized controlled trials, higher total SAFA intakes were not associated with higher incident CHD events or mortality, but replacement nutrients were not taken into account. The effect of reducing dietary SAFA is most strongly affected by the macronutrients that replace them. The greatest reduction in CHD risk occurs when cis-PUFA replace dietary SAFA. In intervention studies replacement of $10 \% \mathrm{E}$ from SAFA by cis-PUFA reduced CVD events by $27 \%$ [4] and the replacement of $5 \% \mathrm{E}$ from SAFA by cis-PUFA decreased CHD risk by $10 \%$ [5]. Data are insufficient to confirm a significant benefit for $\mathrm{CHD}$ risk by substituting cisMUFA for SAFA. Emerging evidence suggests that the food matrix may modify the risk of $\mathrm{CHD}$ associated with some SAFA-rich foods. The consumption of several dairy foods has been associated with a lower risk of CVD, but data are insufficient to justify dietary recommendations.

HDL-C levels are inversely related to CHD risk in healthy populations, but causality is presently doubted. Therefore, the clinical interpretation of the increased HDL-C associated with SAFA consumption is uncertain and warrants further research. Increasing evidence suggests that TG-rich lipoproteins may be a causal risk factor for CHD and stroke.
Other markers for CHD risk, such as LDL particle size and several hemostatic, thrombotic, and inflammatory factors lack a confirmed causal relationship to CHD risk. Consistent evidence for specific effects of SAFA on any of these markers has not been reported.

Studies on SAFA intakes and risk of ischemic stroke are inconsistent. Compared with the abundant data on SAFA consumption and risk of CHD, there is insufficient evidence to support dietary SAFA recommendations to reduce stroke risk.

In conclusion, strong evidence supports the partial replacement of SAFA-rich foods with those rich in cisPUFA to lower LDL-C and reduce CHD risk.

\section{Disclosure Statement}

Financial assistance for this publication, travel funds to attend the SAFA meeting and honoraria were provided to the authors or their institutions from the International Expert Movement to Improve Dietary Fat Quality (IEM; www.theiem.org), the Netherlands Oils and Fats Industry and the Palm Oil Alliance. J.A.N. reports honoraria from Unilever Research and Development. J.M.G. reports grants from Unilever for epidemiological research on dietary and circulating fatty acids in cardiac patients. G.H. reports consultancy fees from the Netherlands Fats and Oils Industry and the European Palm Oil Alliance.

\section{References}

1 de Souza RJ, Mente A, Maroleanu A, Cozma AI, et al: Intake of saturated and trans unsaturated fatty acids and risk of all cause mortality, cardiovascular disease, and type 2 diabetes: systematic review and meta-analysis of observational studies. BMJ 2015;351:h3978.

2 Siri-Tarino PW, Sun Q, Hu FB, Krauss RM: Meta-analysis of prospective cohort studies evaluating the association of saturated fat with cardiovascular disease. Am J Clin Nutr 2010;91:535-546.

3 Jakobsen MU, O'Reilly EJ, Heitmann BL, Pereira MA, et al: Major types of dietary fat and risk of coronary heart disease: a pooled analysis of 11 cohort studies. Am J Clin Nutr 2009;89:1425-1432.

4 Hooper L, Martin N, Abdelhamid A, Davey Smith G: Reduction in saturated fat intake for cardiovascular disease. Cochrane Database Syst Rev 2015;6:CD011737.

5 Mozaffarian D, Micha R, Wallace S: Effects on coronary heart disease of increasing polyunsaturated fat in place of saturated fat: a systematic review and meta-analysis of randomized controlled trials. PLoS Med 2010;7: e1000252.

6 Mensink RP: Effects of Saturated Fatty Acids on Serum Lipids and Lipoproteins: A System- atic Review and Regression Analysis. Geneva, World Health Organization, 2016.

7 Ridker PM: LDL cholesterol: controversies and future therapeutic directions. Lancet 2014;384:607-617.

8 DiNicolantonio JJ: The cardiometabolic consequences of replacing saturated fats with carbohydrates or $\Omega-6$ polyunsaturated fats: do the dietary guidelines have it wrong? Open Heart 2014;1:e000032.

9 Hoenselaar R: Saturated fat and cardiovascular disease: the discrepancy between the scientific literature and dietary advice. Nutrition 2012;28:118-123.

10 Eilander A, Harika RK, Zock PL: Intake and sources of dietary fatty acids in Europe: are current population intakes of fats aligned with dietary recommendations? Eur J Lipid Sci Technol 2015;117:1370-1377.

11 US Department of Agriculture, Agricultural Research Service: National Nutrient Database for Standard Reference, Release 28; Fats and Oils. US Department of Agriculture. 2015. https://ndb.nal.usda.gov/ndb/search/ list.

12 Harika RK, Eilander A, Alssema M, Osendarp SJ, et al: Intake of fatty acids in general populations worldwide does not meet dietary recommendations to prevent coronary heart disease: a systematic review of data from 40 countries. Ann Nutr Metab 2013;63:229238.

13 Kubow S: The influence of positional distribution of fatty acids in native, interesterified and structure-specific lipids on lipoprotein metabolism and atherogenesis. J Nutr Biochem 1996;7:530-541.

14 Berry SE: Triacylglycerol structure and interesterification of palmitic and stearic acid-rich fats: an overview and implications for cardiovascular disease. Nutr Res Rev 2009;22:3-17.

15 Eyres L, Eyres MF, Chisholm A, Brown RC: Coconut oil consumption and cardiovascular risk factors in humans. Nutr Rev 2016;74: 267-280.

16 Chamberlain LH, Shipston MJ: The physiology of protein S-acylation. Physiol Rev 2015; 95:341-376.

17 Wedegaertner PB: Lipid modifications and membrane targeting of $\mathrm{G}$ alpha. Biol Signals Recept 1998;7:125-135.

18 Beauchamp E, Goenaga D, Le Bloc'h J, Catheline D, et al: Myristic acid increases the activity of dihydroceramide delta4-desaturase 1 through its N-terminal myristoylation. Biochimie 2007;89:1553-1561. 
19 Dabadie H, Peuchant E, Bernard M, LeRuyet $\mathrm{P}$, et al: Moderate intake of myristic acid in sn-2 position has beneficial lipidic effects and enhances DHA of cholesteryl esters in an interventional study. J Nutr Biochem 2005;16: 375-382.

20 Patel AR, Dewettinck K: Edible oil structuring: an overview and recent updates. Food Funct 2016;7:20-29.

21 Hamm W, Hamilton RJ, Calliauw G (eds): Edible Oil Processing, ed 2. Wiley-Blackwell, 2013, p 342.

22 Marangoni AG, Wesdorp LH: Structure and Properties of Fat Crystal Networks, ed 2. CRC Press, 2012

23 Norlida HM, Md Ali AR, Muhadhir I: Blending of palm oil, palm stearin and palm kernel oil in the preparation of table and pastry margarine. Int J Food Sci Nutr 1996;47:71-74.

24 Wong ND: Epidemiological studies of CHD and the evolution of preventive cardiology. Nat Rev Cardiol 2014;11:276-289.

25 Davey Smith G, Hemani G: Mendelian randomization: genetic anchors for causal inference in epidemiological studies. Hum Mol Genet 2014;23:R89-R98.

26 Marz W, Scharnagl H, Gouni-Berthold I, Silbernagel G, et al: LDL-cholesterol: standards of treatment 2016: a German perspective. Am J Cardiovasc Drugs 2016;16:323-336.

27 Jacobs DR Jr, Anderson JT, Blackburn H: Diet and serum cholesterol: do zero correlations negate the relationship? Am J Epidemiol 1979;110:77-87.

28 Jacobson TA, Maki KC, Orringer CE, Jones $\mathrm{PH}$, et al: National lipid association recommendations for patient-centered management of dyslipidemia: part 2. J Clin Lipidol 2015;9:S1-S122.e1.

29 Berneis KK, Krauss RM: Metabolic origins and clinical significance of LDL heterogeneity. J Lipid Res 2002;43:1363-1379.

30 Hoogeveen RC, Gaubatz JW, Sun W, Dodge $\mathrm{RC}$, et al: Small dense low-density lipoprotein-cholesterol concentrations predict risk for coronary heart disease: the Atherosclerosis Risk In Communities (ARIC) study. Arterioscler Thromb Vasc Biol 2014;34: 1069-1077.

31 Melander O, Shiffman D, Caulfield MP, Louie JZ, et al: Low-density lipoprotein particle number is associated with cardiovascular events among those not classified into statin benefit groups. J Am Coll Cardiol 2015;65: 2571-2573.

32 Dreon DM, Fernstrom HA, Miller B, Krauss RM: Low-density lipoprotein subclass patterns and lipoprotein response to a reducedfat diet in men. FASEB J 1994;8:121-126.

33 Mangravite LM, Chiu S, Wojnoonski K, Rawlings RS, et al: Changes in atherogenic dyslipidemia induced by carbohydrate restriction in men are dependent on dietary protein source. J Nutr 2011;141:2180-2185.

34 Krauss RM, Blanche PJ, Rawlings RS, Fernstrom HS, et al: Separate effects of reduced carbohydrate intake and weight loss on ath- erogenic dyslipidemia. Am J Clin Nutr 2006; 83:1025-1031; quiz 1205.

35 Sacks FM, Svetkey LP, Vollmer WM, Appel LJ, et al: Effects on blood pressure of reduced dietary sodium and the Dietary Approaches to Stop Hypertension (DASH) diet. DASHSodium Collaborative Research Group. N Engl J Med 2001;344:3-10.

36 Chiu S, Bergeron N, Williams PT, Bray GA, et al: Comparison of the DASH (Dietary Approaches to Stop Hypertension) diet and a higher-fat DASH diet on blood pressure and lipids and lipoproteins: a randomized controlled trial. Am J Clin Nutr 2016;103:341347.

37 Krauss RM: All low-density lipoprotein particles are not created equal. Arterioscler Thromb Vasc Biol 2014;34:959-961.

38 Gordon T, Castelli WP, Hjortland MC, Kannel WB, et al: High density lipoprotein as a protective factor against coronary heart disease. The Framingham study. Am J Med 1977; 62:707-714.

39 Emerging Risk Factors Collaboration, Di Angelantonio E, Sarwar N, Perry P, et al: Major lipids, apolipoproteins, and risk of vascular disease. JAMA 2009;302:1993-2000.

40 Fielding CJ, Fielding PE: Cholesterol transport between cells and body fluids. Role of plasma lipoproteins and the plasma cholesterol esterification system. Med Clin North Am 1982;66:363-373.

41 Rader DJ: Spotlight on HDL biology: new insights in metabolism, function, and translation. Cardiovasc Res 2014;103:337-340.

42 Zanoni P, Khetarpal SA, Larach DB, Hancock-Cerutti WF, et al: Rare variant in scavenger receptor BI raises HDL cholesterol and increases risk of coronary heart disease. Science 2016;351:1166-1171.

43 Keene D, Price C, Shun-Shin MJ, Francis DP: Effect on cardiovascular risk of high density lipoprotein targeted drug treatments niacin, fibrates, and CETP inhibitors: meta-analysis of randomised controlled trials including 117,411 patients. BMJ 2014;349:g4379.

44 Annema W, von Eckardstein A: Dysfunctional high-density lipoproteins in coronary heart disease: implications for diagnostics and therapy. Transl Res 2016;173:30-57.

45 Rohatgi A, Khera A, Berry JD, Givens EG, et al: HDL cholesterol efflux capacity and incident cardiovascular events. N Engl J Med 2014;371:2383-2393.

46 Hegele RA, Ginsberg HN, Chapman MJ, Nordestgaard BG, et al: The polygenic nature of hypertriglyceridaemia: implications for definition, diagnosis, and management. Lancet Diabetes Endocrinol 2014;2:655-666.

47 Nordestgaard BG, Varbo A: Triglycerides and cardiovascular disease. Lancet 2014;384:626635.

48 Nordestgaard BG, Benn M, Schnohr P, Tybjaerg-Hansen A: Nonfasting triglycerides and risk of myocardial infarction, ischemic heart disease, and death in men and women. JAMA 2007;298:299-308.
49 Sarwar N, Danesh J, Eiriksdottir G, Sigurdsson G, et al: Triglycerides and the risk of coronary heart disease: 10,158 incident cases among 262,525 participants in 29 Western prospective studies. Circulation 2007;115: 450-458.

50 Graham I, Cooney MT, Bradley D, Dudina A, et al: Dyslipidemias in the prevention of cardiovascular disease: risks and causality. Curr Cardiol Rep 2012;14:709-720.

51 Varbo A, Nordestgaard BG: Remnant cholesterol and ischemic heart disease. Curr Opin Lipidol 2014;25:266-273.

52 Jeppesen J, Hein HO, Suadicani P, Gyntelberg F: Triglyceride concentration and ischemic heart disease: an eight-year follow-up in the Copenhagen male study. Circulation 1998;97: 1029-1036

53 Nordestgaard BG: Triglyceride-rich lipoproteins and atherosclerotic cardiovascular disease: new insights from epidemiology, genetics, and biology. Circ Res 2016;118:547-563.

54 Jorgensen AB, Frikke-Schmidt R, West AS, Grande $P$, et al: Genetically elevated non-fasting triglycerides and calculated remnant cholesterol as causal risk factors for myocardial infarction. Eur Heart J 2013;34:1826-1833.

55 Triglyceride Coronary Disease Genetics Consortium and Emerging Risk Factors Collaboration, Sarwar N, Sandhu MS, et al: Triglyceride-mediated pathways and coronary disease: collaborative analysis of 101 studies. Lancet 2010;375:1634-1639.

$56 \mathrm{Li} \mathrm{Y,} \mathrm{Li} \mathrm{C,} \mathrm{Gao} \mathrm{J:} \mathrm{Apolipoprotein} \mathrm{C3} \mathrm{gene} \mathrm{vari-}$ ants and the risk of coronary heart disease: a meta-analysis. Meta Gene 2016;9:104-109.

57 Jorgensen $A B$, Frikke-Schmidt R, Nordestgaard BG, Tybjærg-Hansen A: Loss-of-function mutations in APOC3 and risk of ischemic vascular disease. N Engl J Med 2014;371: $32-41$.

58 Emerging Risk Factors Collaboration, Kaptoge S, Di Angelantonio E, Pennells L, et al: $\mathrm{C}$-reactive protein, fibrinogen, and cardiovascular disease prediction. N Engl J Med 2012; 367:1310-1320.

59 Lowe G, Rumley A: The relevance of coagulation in cardiovascular disease: what do the biomarkers tell us? Thromb Haemost 2014; 112:860-867.

60 Go AS, Bauman MA, Coleman King SM, Fonarow GC, et al: An effective approach to high blood pressure control: a science advisory from the American Heart Association, the American College of Cardiology, and the Centers for Disease Control and Prevention. Hypertension 2014;63:878-885.

61 Sima AV, Stancu CS, Simionescu M: Vascular endothelium in atherosclerosis. Cell Tissue Res 2009;335:191-203.

62 Okwuosa TM, Klein O, Chan C, Jenny NS, et al: 13-year long-term associations between changes in traditional cardiovascular risk factors and changes in fibrinogen levels: the Coronary Artery Risk Development in Young Adults (CARDIA) study. Atherosclerosis 2013;226:214-219. 
63 Gilmour KM, Iversen L, Hannaford PC: Long-term survival benefits of thrombolysis: the Royal College of General Practitioners' myocardial infarction study. Fam Pract 2015; 32:192-197.

64 Kannel WB: Overview of hemostatic factors involved in atherosclerotic cardiovascular disease. Lipids 2005;40:1215-1220.

65 Sabater-Lleal M, Huang J, Chasman D, Naitza $S$, et al: Multiethnic meta-analysis of genomewide association studies in $>100000$ subjects identifies 23 fibrinogen-associated Loci but no strong evidence of a causal association between circulating fibrinogen and cardiovascular disease. Circulation 2013;128:13101324.

66 Cooper JA, Miller GJ, Bauer KA, Morrissey $\mathrm{JH}$, et al: Comparison of novel hemostatic factors and conventional risk factors for prediction of coronary heart disease. Circulation 2000;102:2816-2822.

67 Meade TW, Mellows S, Brozovic M, Miller GJ, et al: Haemostatic function and ischaemic heart disease: principal results of the Northwick Park Heart Study. Lancet 1986;2: 533-537.

68 Willeit $\mathrm{P}$, Thompson A, Aspelund T, Rumley A, et al: Hemostatic factors and risk of coronary heart disease in general populations: new prospective study and updated meta-analyses. PLoS One 2013;8:e55175.

69 Woodward M, Rumley A, Welsh P, MacMahon S, et al: A comparison of the associations between seven hemostatic or inflammatory variables and coronary heart disease. J Thromb Haemost 2007;5:1795-1800.

70 Joint FAO/WHO Expert Consultation: Fats and Fatty Acids in Human Nutrition. Geneva, FAO/WHO, 2008.

71 Chowdhury R, Warnakula S, Kunutsor S, Crowe F, et al: Association of dietary, circulating, and supplement fatty acids with coronary risk: a systematic review and meta-analysis. Ann Intern Med 2014;160:398-406.

72 Skeaff CM, Miller J: Dietary fat and coronary heart disease: summary of evidence from prospective cohort and randomised controlled trials. Ann Nutr Metab 2009;55:173-201.

73 Li Y, Hruby A, Bernstein AM, Ley SH, et al: Saturated fats compared with unsaturated fats and sources of carbohydrates in relation to risk of coronary heart disease: a prospective cohort study. J Am Coll Cardiol 2015;66: 1538-1548.

74 Praagman J, Beulens JW, Alssema M, Zock PL, et al: The association between dietary saturated fatty acids and ischemic heart disease depends on the type and source of fatty acid in the European Prospective Investigation into Cancer and Nutrition-Netherlands cohort. Am J Clin Nutr 2016;103:356-365.

75 Praagman J, de Jonge EA, Kiefte-de Jong JC, Beulens JW, et al: Dietary saturated fatty acids and coronary heart disease risk in a Dutch middle-aged and elderly population. Arterioscler Thromb Vasc Biol 2016;36: 2011-2018.

76 Astrup A, Dyerberg J, Elwood P, Hermansen $\mathrm{K}$, et al: The role of reducing intakes of saturated fat in the prevention of cardiovascular disease: where does the evidence stand in 2010? Am J Clin Nutr 2011;93:684-688.

77 Khaw KT, Friesen MD, Riboli E, Luben R, et al: Plasma phospholipid fatty acid concentration and incident coronary heart disease in men and women: the EPIC-Norfolk prospective study. PLoS Med 2012;9:e1001255.

78 Schwab U, Lauritzen L, Tholstrup T, Haldorssoni $\mathrm{T}$, et al: Effect of the amount and type of dietary fat on cardiometabolic risk factors and risk of developing type 2 diabetes, cardiovascular diseases, and cancer: a systematic review. Food Nutr Res 2014;58.

79 Faghihnia N, Mangravite LM, Chiu S, Bergeron N, et al: Effects of dietary saturated fat on LDL subclasses and apolipoprotein CIII in men. Eur J Clin Nutr 2012;66:1229-1233.

80 de Oliveira Otto MC, Mozaffarian D, Kromhout D, Bertoni AG, et al: Dietary intake of saturated fat by food source and incident cardiovascular disease: the Multi-Ethnic Study of Atherosclerosis. Am J Clin Nutr 2012;96:397404.

81 Soedamah-Muthu SS, Ding EL, Al-Delaimy $\mathrm{WK}, \mathrm{Hu} \mathrm{FB}$, et al: Milk and dairy consumption and incidence of cardiovascular diseases and all-cause mortality: dose-response metaanalysis of prospective cohort studies. Am J Clin Nutr 2011;93:158-171.

82 de Goede J, Geleijnse JM, Ding EL, Soedamah-Muthu SS: Effect of cheese consumption on blood lipids: a systematic review and metaanalysis of randomized controlled trials. Nutr Rev 2015;73:259-275.

83 Vors C, Pineau G, Gabert L, Drai J, et al: Modulating absorption and postprandial handling of dietary fatty acids by structuring fat in the meal: a randomized crossover clinical trial. Am J Clin Nutr 2013;97:23-36.

84 Miller GJ: Dietary fatty acids and the haemostatic system. Atherosclerosis 2005; 179:213227.

85 Hornstra G, Kester AD: Effect of the dietary fat type on arterial thrombosis tendency: systematic studies with a rat model. Atherosclerosis 1997;131:25-33.
86 Pieters M, de Maat MP: Diet and haemostasis - a comprehensive overview. Blood Rev 2015; 29:231-241.

87 Blood Pressure Lowering Treatment Trialists' Collaboration, Sundstrom J, Arima H, Woodward $\mathrm{M}$, et al: Blood pressure-lowering treatment based on cardiovascular risk: a metaanalysis of individual patient data. Lancet 2014;384:591-598.

88 Lawes CM, Bennett DA, Lewington S, Rodgers A: Blood pressure and coronary heart disease: a review of the evidence. Semin Vasc Med 2002;2:355-368.

89 Lewington S, Clarke R, Qizilbash N, Peto R, et al: Age-specific relevance of usual blood pressure to vascular mortality: a meta-analysis of individual data for one million adults in 61 prospective studies. Lancet 2002;360:1903-1913.

90 Cheng P, Wang J, Shao W, Liu M, et al: Can dietary saturated fat be beneficial in prevention of stroke risk? A meta-analysis. Neurol Sci 2016;37:1089-1098.

91 Chen M, Li Y, Sun Q, Pan A, et al: Dairy fat and risk of cardiovascular disease in 3 cohorts of US adults. Am J Clin Nutr 2016;104:12091217.

92 Yakoob MY, Shi P, Hu FB, Campos H, et al: Circulating biomarkers of dairy fat and risk of incident stroke in U.S. men and women in 2 large prospective cohorts. Am J Clin Nutr 2014;100:1437-1447.

93 Alexander DD, Bylsma LC, Vargas AJ, Cohen SS, et al: Dairy consumption and CVD: a systematic review and meta-analysis. Br J Nutr 2016;115:737-750.

94 Qin LQ, Xu JY, Han SF, Zhang ZL, et al: Dairy consumption and risk of cardiovascular disease: an updated meta-analysis of prospective cohort studies. Asia Pac J Clin Nutr 2015;24: 90-100.

95 Nordic Council of Ministers: Nordic Nutrition Recommendations 2012. Integrating nutrition and physical activity. Copenhagen, Nordic Council of Ministers, 2014.

96 US Department of Health and Human -Services and US Department of Agriculture: 2015-2020 Dietary Guidelines for Americans, ed 8. Washington, US Department of Health and Human Services, 2015.

97 Kromhout D, Spaaij CJ, de Goede J, Weggemans RM: The 2015 Dutch food-based dietary guidelines. Eur J Clin Nutr 2016;70:869878.

98 Zong G, Li Y, Wanders AJ, Alssema M, et al: Intake of individual saturated fatty acids and risk of coronary heart disease in US men and women: two prospective longitudinal cohort studies. BMJ 2016;355:i5796. 